\title{
Increased methylation at differentially methylated region of GNAS in infants born to gestational diabetes
}

Danqing Chen ${ }^{1+}$, Aiping Zhang ${ }^{2+}$, Min Fang ${ }^{3}$, Rong Fang ${ }^{4}$, Jiamei Ge ${ }^{5}$, Yuan Jiang ${ }^{6}$, Hong Zhang ${ }^{7}$, Cong Han ${ }^{1}$, Xiaoqun $\mathrm{Ye}^{1}$, Hefeng Huang ${ }^{1,9}$, Yun Liu ${ }^{7,8^{*}}$ and Minyue Dong ${ }^{1,9,10^{*}}$

\begin{abstract}
Background: Offspring of pregnancy complicated with gestational diabetes (GDM) are at high risk for metabolic diseases. The mechanisms behind the association of intrauterine exposure to GDM and high risk of health problems in later life remain largely unknown. The aim of this study was to clarify the alteration in methylation levels at differentially methylated regions (DMRs) of GNAS and IGF2 in fetuses of GDM women and to explore the possible mechanisms linking maternal GDM with high risk of metabolic diseases in later life of GDM offspring.

Methods: Lymphocytes were isolated from umbilical cord blood of infants born to 87 women with GDM and 81 women with normal pregnancy. Genomic DNA was extracted and DNA methylation levels of GNAS and IGF2 DMRs were determined by Massarray quantitative methylation analysis.
\end{abstract}

Results: The methylation levels were detected in 7 CpG sites of GNAS DMRs and 6 sites of IGF2 DMRs. Methylation levels were significantly higher at sites 4, 5 and 7 of GNAS DMR in GDM compared to normal pregnancy ( $P=0.007,0.008$ and 0.008 , respectively). The methylation level at site 4 of GNAS was significantly correlated with the presence of GDM $(P=0.003)$, the methylation levels at site 5 and 7 were significantly correlated with the presence of GDM ( $P=0.002$ for both) and gestational age ( $P=0.027$ for both). There was no significant difference in any sites of IGF2 DMR ( $P>0.05$ for all).

Conclusions: We concluded maternal GDM-induced hypermethylation at GNAS DMR and this condition may be among the mechanisms associating maternal GDM with increased risk of metabolic diseases in later life of offspring.

Keywords: Gestational diabetes mellitus, Methylation, DNA, DMR, GNAS, IGF2

\section{Background}

Gestational diabetes mellitus (GDM), defined as any degree of glucose intolerance with onset or first recognition during pregnancy, affects $2-12 \%$ of all pregnancies $[1,2]$. GDM is associated with adverse pregnancy outcomes, including macrosomia and subsequently birth trauma, and fetal hypoglycemia, hypocalcaemia, respiratory distress, and even stillbirth, whereas treatments of GDM improve pregnancy outcomes [3,4]. GDM poses life-long risk to the offspring, such as increased birth

\footnotetext{
*Correspondence: superliuyun@gmail.com; mydong.cn@hotmail.com ${ }^{\dagger}$ Equal contributors

'Institutes of Biomedical Sciences, Fudan University, Shanghai, China 'Women's Hospital, School of Medicine, Zhejiang University, 1 Xueshi Road, Hangzhou 310006, Zhejiang Province, China

Full list of author information is available at the end of the article
}

weight, higher BMI at age of 6-24 and incidence of adolescent obesity compared to controls [5-7]. Numeral studies have shown an increase in metabolic syndrome in offspring of GDM pregnancies [8]. The prevalence of impaired glucose tolerance is higher in the offspring of mothers with gestational and pre-gestational diabetes than those of background population [9-12]. Animal studies revealed metabolic imprinting of intrauterine diabetic environment can be transmitted across generations [13]. Although studies in human and animal have demonstrated the association of GDM and risk of obesity, diabetes and metabolic diseases in offspring of GDM pregnancies, the mechanisms behind remain elusive.

Epigenetic modification might be among the mechanisms underlying this association [14]. The persistent epigenetic 
change in imprinted genes induced by prenatal environment may be among the mechanisms contributing to the association between maternal GDM and health problems in later life of offspring. Imprinted genes play important roles in embryonic growth and development and epigenetic disruption due to adversity in early life may be associated with susceptibility to metabolic diseases [15]. GDM induces differential methylation of genes in fetal DNA from offspring born to GDM mothers. Ruchat et al. [16] reported that GDM has epigenetic effects on genes preferentially involved in the metabolic diseases pathway and proposed that DNA methylation is involved in fetal metabolic and developmental programming. Differential methylation of fetal MEST and ABCA1 was also observed $[17,18]$.

Insulin-like growth factor 2 (IGF2) is a paternally expressed gene widely expressed during prenatal development and its activity is regulated by genomic imprinting. Imprinted expression of IGF2 is partially maintained through the differentially methylated region (DMR) located between exon 2 and 3, the disrupted methylation of which is associated with congenital growth disorders $[19,20]$. Guanine nucleotide binding protein alpha subunit $(G N A S)$ is an imprinted gene with a highly complex imprinted expression pattern, which gives rise to maternally, paternally, and biallelically expressed transcripts $[21,22]$. The imprinted expression of GNAS is controlled by the DMR in exon $1 \mathrm{~A}$ [23]. The methylation at differentially methylated region (DMR) of imprinted genes is established before gastrulation and is very sensitive to early developmental environment, but can be relatively stable throughout the life of individual $[21,22]$. The investigations in subjects conceived during Dutch famine winter revealed that the exposure to prenatal famine resulted in the persistent alteration in DNA methylation of imprinted genes including GNAS and IGF2 [24,25]. Small-for-gestational age (SGA) and preeclampsia, conditions characterized by poor nutrient supply to fetus, induces hypomethylation at IGF2 and GNAS DMRs and altered methylation at DMRs of imprinted genes may subsequently contribute to the development of metabolic diseases in later life [22,26-28]. However, the effect of GDM, a condition apposite to SGA and preeclampsia, on the methylation at DMRs of IGF2 and GNAS of fetus has not been described yet.

In addition, although both of GNAS and IGF2 gene are associated with obesity [29,30] and hypertension [31-34], currently there is no evidence if GDM modifies epigenetic imprints of GNAS and IGF2 of fetus, or, GNAS and IGF2 are possibly involved in the induction of high risk of GDM-related metabolic diseases in adulthood. Therefore, we determined fetal methylation levels at GNAS and IGF2 DMRs of GDM and normal pregnancy in this study, and found increased methylation at
GNAS DMR in fetuses of GDM compared to normal pregnancy.

\section{Methods}

\section{Subjects}

Eighty-seven women of GDM and 81 normal pregnant women were recruited in Women's Hospital, School of Medicine, Zhejiang University, Shaoxing Women and Children's Hospital, Ningbo Women and Children's Hospital, Huzhou Maternity and Child Care Hospital and Jiaxing Maternity and Child Care Hospital.

Pregnancy was diagnosed upon positive human chorionic gonadotropin (hCG) test after missed menstruation. Gestational age was calculated by menstrual dating. Ultrasound was performed to confirm pregnancy and gestational age. GDM was diagnosed according to the criteria recommended by International Association of Diabetes and Pregnancy Study Groups (IADPSG) [35]. All GDM women controlled their glycemia with dietary control and physical activity. Exclusion criteria were multiple gestation, diabetes mellitus, chronic hypertension, infectious diseases recognized in pregnancy, premature rupture of membrane, active labor, polyhydramnios and signs of other concurrent medical complication. The control women had no sign of gestational complications and fetal distress and gave birth to healthy neonates of appropriate size for gestational age.

Clinical data and demographic data were collected according to the medical records. The approval of the current study was obtained from Institutional Ethical committee of Women's Hospital, School of Medicine, Zhejiang University, and all the participants provided their informed consents.

\section{DNA methylation analysis}

Umbilical cord blood samples were collected in Ethylene Diamine Tetraacetic Acid (EDTA)-treated tubes at delivery. Lymphocytes of infants were isolated and stored at $-80 \mathrm{C}$ until use. Total DNA was isolated from lymphocytes using buffer ATL, proteinase K, and RNase A (Qiagen, Inc., Valencia, CA) followed by phenol-chloroform extraction and ethanol precipitation. Bisulfite conversion of DNA was carried out using the Epitect Bisulfite Kit (Qiagen Inc., Valencia, CA).

Quantitative methylation analysis of DNA was performed using MassARRAY EpiTYPER assays (Sequenom, San Diego, CA) according to the protocol recommended by the manufacturer. Methylation of all CpG sites at the IGF2 DMR in Chr11: 2169100-2169551, and GNAS DMR in Chr 20: 57,415,713-57,416,072 was measured, quantitative methylation of each CpG unit was calculated following the method described in our previous study [28]. Seven CpG sites in the GNAS DMR and six CpG sites in the IGF2 DMR were qualified for reliable detection based on $\mathrm{CpG}$ unit mass quality evaluated by EpiTYPER and 
were used for the further statistic analysis. The other CpG sites in the DMRs were discarded as they are either nonquantifiable or ambiguous CpG sites. Positions of each CpG site was stated in our previous study [28].

\section{Statistical analysis}

The Kolmogorov-Smirnov test was used to evaluate the distribution of data. Continuous data were presented in mean and standard deviation (SD) and compared with Student $t$-tests while categorical data were evaluated with Chi-square test. Multiple variant regression analysis was used to evaluate the relationship of methylation level with the presence of GDM, birth weight, maternal age, gestational age at delivery and fetal gender. SPSS statistical package (Statistical Analysis System, Chicago, IL) was used for the statistic analysis. Values of $\mathrm{P}<0.05$ were considered to be statistically significant.

\section{Results}

As shown in Table 1, there were significant differences in maternal age, gestational age at delivery and neonatal birth weight between GDM and normal pregnancy $(\mathrm{P}<0.001$ for all). Maternal age was greater, gestational age was shorter and birth weight was heavier in GDM group compared to normal pregnancy. There was no significant difference in fetal gender $(\mathrm{P}=0.504)$.

The methylation levels were detected in $7 \mathrm{CpG}$ sites of GNAS DMRs and 6 sites of IGF2 DMRs (Figures 1 and 2). Methylation levels at sites 4, 5 and 7 of GNAS DMR were significantly higher in GDM compared to normal pregnancy $(P=0.007,0.008$ and 0.008 , respectively), but there were no significant differences in methylation levels at sites $2,8,9$ and 12 ( $\mathrm{P}=0.254,0.122,0.254$ and 0.077 , respectively). The methylation level of CpG site 4, 5 and 7 of GNAS DMR were significantly correlated with the presence of GDM ( $P=0.003 ; P=0.002$ for site 5 and 7$)$, furthermore, the methylation levels of sites 5 and 7 were significantly correlated with gestational age ( $\mathrm{P}=0.027$ for both).

There were no significant differences in methylation levels at CpG sites 3, 4, 6, 7, 9 and 10 of IGF2 DMR between GDM and normal pregnancy $(\mathrm{P}=0.792,0.840$, $0.455,0.784,0.845$ and 0.214 , respectively). When it comes to the mean methylation levels of all those CpGs sites at the GNAS and IGF2 DMRs, there were not significantly different between GDM and normal pregnancy $(\mathrm{P}=0.271$ and 0.689 , respectively)(Table 1$)$.

\section{Discussion}

In the current investigation, increased methylation in CpGs sites of GNAS DMR was observed in fetuses of GDM women compared to control. Our data imply that increased methylation at GNAS DMR may be among the mechanisms linking maternal GDM with high risk of metabolic diseases in later life of fetuses. Whereas, unchanged methylation at IGF2 DMR indicate IGF2 is not vulnerable to GDM-induced intrauterine environment.

GNAS, the gene encoding G protein alpha (GS $\alpha$ ), is imprinted in a tissue-specific manner. There are three DMRs located from upstream to downstream of the GS $\alpha$ promoter: the first one is in the NESP55 promoter region, the second is in the NESPAS/GNASXL promoter region and the third one is located in the GNAS exon 1A region. The Exon 1A DMR controlls the imprinted expression of GNAS [20]. GS $\alpha$ is equally expressed from both alleles in most tissues, but is expressed primarily from the maternal allele in certain hormone-target tissues, such as thyroid and pituitary et al. [36,37]. The DMR analyzed in our study, which is located in the exon 1A DMR, is necessary for tissue-specific imprinting of GS $\alpha$ [23]. GS $\alpha$ plays an important role in energy metabolism and the development of obesity [29]. The mutations of GNAS which disrupt GSa expression or function cause Albright hereditary osteodystrophy (AHO), a congenital syndrome which is characterized by obesity, short stature

Table 1 Clinical data and mean methylation levels at GNAS and IGF2 DMRs

\begin{tabular}{llll}
\hline & Normal pregnancy & Gestational diabetes & Significance \\
\hline $\mathrm{n}$ & 81 & 87 & \\
Maternal characteristic & & $30.61 \pm 3.8$ & $<0.001$ \\
$\quad$ Maternal age $(\mathrm{y})$ & $28.6 \pm 3.4$ & $37.56 \pm 1.86$ & \\
$\quad$ Gestational age at delivery $(\mathrm{w})$ & $38.70 \pm 1.37$ & $3559 \pm 592$ & $<01$ \\
Infant characteristics & & Male:45 & 0.001 \\
$\quad$ Birth weight (g) & $3288 \pm 395$ & Female:42 \\
$\quad$ Fetal gender & Male:41 & & 0.504 \\
& Female:40 & $0.52 \pm 0.059$ & $0.46 \pm 0.048$ \\
Methylataion data & & $0.51 \pm 0.056$ & 0.689 \\
$\quad$ methylation level at GNAS DMR & $0.46 \pm 0.043$ & \\
\hline
\end{tabular}




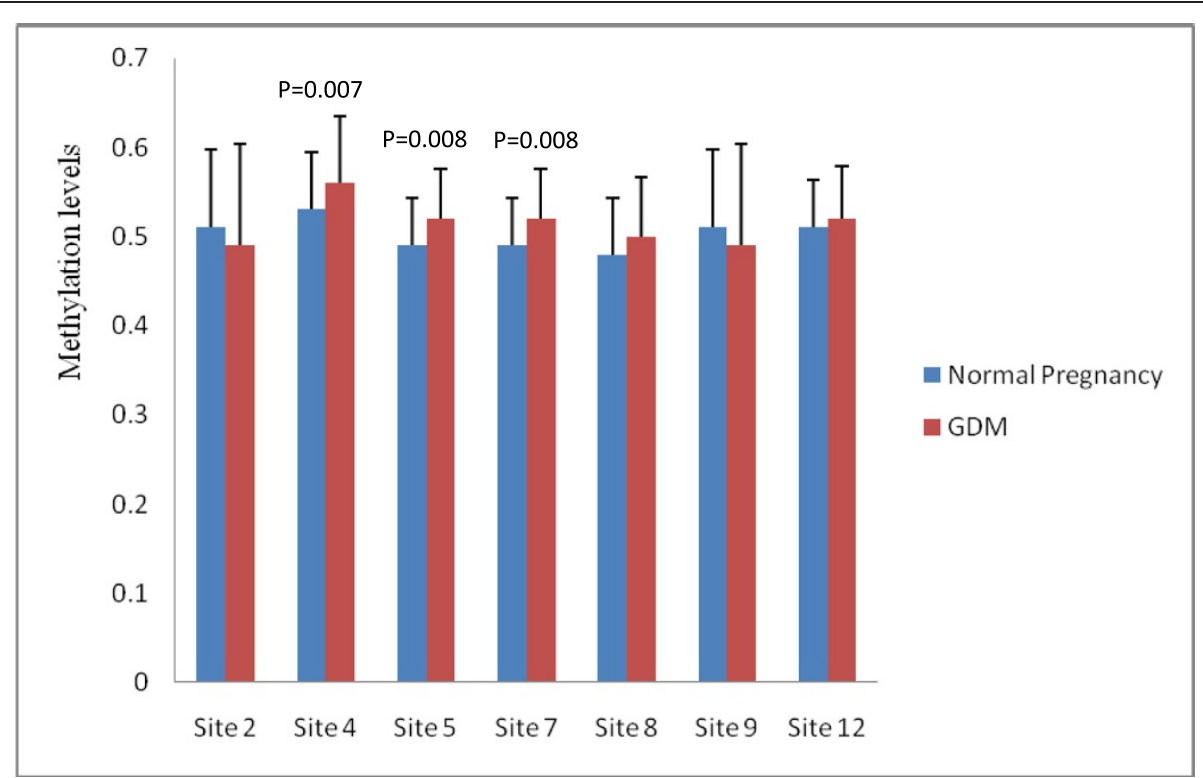

Figure 1 Site-specific methylation levels at GNAS DMR in fetuses of normal pregnancy and gestational diabetes (GDM). There were significant differences in methylation levels at site 4, 5 and 7 between fetuses of normal pregnancy and GDM $(P=0.007,0.008$ and 0.008 , respectively). The differences were not significant in the methylation levels at site $2,8,9$ and 12 ( $P=0.254,0.122,0.254$ and 0.077 , respectively).

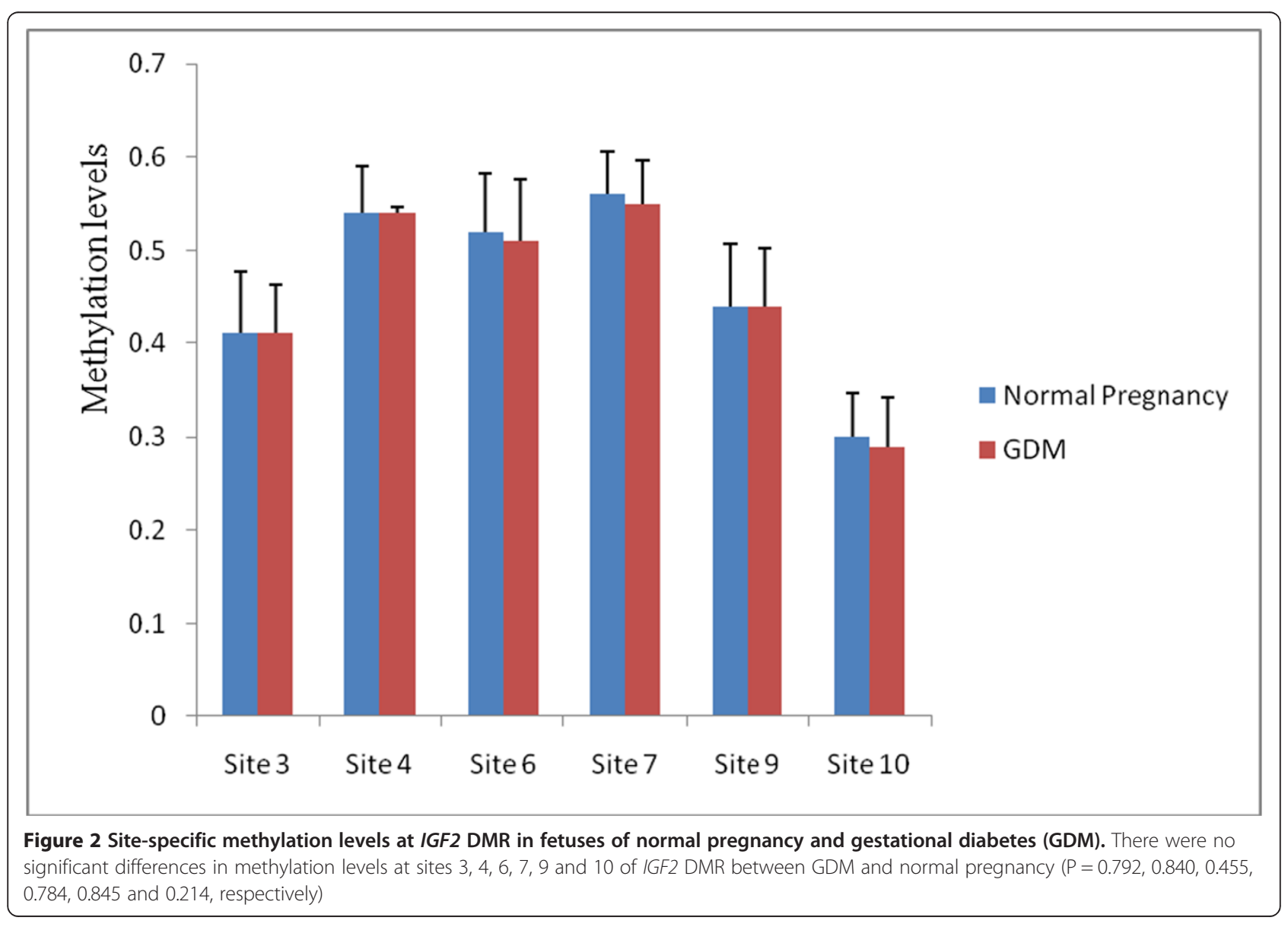


et al. [29,30]. Patients of AHO with mutation located on the maternal allele develop resistance to hormones including parathyroid hormone, thyrotropin, growth hormonereleasing hormone and gonadotropins. In this condition, obesity occurs very early (usually within the first year) and tends to be severe in early childhood. In addition, animal study showed that GNAS knock-out mice with an insertion mutation on maternal allele develops obesity with increased serum leptin levels and lipid accumulation [38].

It was reported that prenatal exposure to adverse environment, such as disturbed intrauterine environment, dysregulates the fetal epigenome, with potential consequences for subsequent developmental disorders and disease over the life course [39]. However, no literature describing the effects of GDM on fetal GNAS was available yet. Herein, we reported for the first time the increased methylation at GNAS DMR in GDM fetuses compared to control, indicating methylation of GNAS DMR is sensitive to GDM-induced intrauterine environment. Regression analysis excluded the confounder effect of maternal age and birth weight on methylation in GNAS DMR but we could neither exclude the possible effect of gestational age nor determine the causal relationship between GDM and hypermethylation of GNAS DMR. As disruption in the imprinted expression of GS $\alpha$ leads to the development of obesity, our data also provide a clue to mechanisms linking maternal GDM with risk to chronic diseases for infants in adulthood, such as obesity. Further evidence linking increased methylation at GNAS DMR with the expression or function of GS $\alpha$ in a tissue-specific manner would enhance our insight into the role of increased methylation at GNAS in the development of obesity. Animal models or cell lines are needed for these purposes.

In this paper, we also analyzed differences of methylation levels in the IGF2 DMR in fetuses of GDM women comparing to control. The imprinting of IGF2 is maintained by two regulatory DMRs located close to exon 3 (also referred to IGF2 DMR or DMR0) and upstream of neighboring maternally expressed $H 19$ (referred to H19 DMR). Multiple CpG sites in the IGF2 DMR were found to be associated with higher newborn birth and placenta weight, while no significant association was observed in the H19 DMR [40]. In addition, hypomethylation of IGF2 DMR was also associated with elevated plasma IGF2 protein concentrations and higher birth weight in infant born to obesity women while patterns of association were not apparent at the H19 DMR [41]. Another study revealed that the methylation levels of IGF2 DMR were affected by folic acid intake before or during pregnancy and depression in pregnancy [42]. Taken together with our previous study reported significant lower methylation in offspring of preeclampsia than normal pregnancy [28], it indicates that the methylation of IGF2
DMR could be a better biomarker than H19 DMR to evaluated the effect of environmental exposure in early development. Therefore, we investigated the association between methylation levels of the IGF2 DMR located between the exon 2 and 3 of IGF2 with intrauterine exposure to GDM. However, our study failed to find significant methylation changes of IGF2 DMR between infants born to GDM mother and normal control. The lack of association between the IGF2 DMR methylation profile and GDM in our study indicated that the IGF2 DMR may not be vulnerable to GDM-induced intrauterine environment.

However, animal studies revealed hypermethylation at IGF in diabetic offspring. Shao et al. reported that the methylation level of the H19-Igf2 imprint control region was $19.1 \%$ higher while the body weight was $26.5 \%$ lower in pups born to diabetic mice compared to controls [43]. Ding et al. observed hypermethylation at H19-Igf2 DMRs and reduced expression of IGF2 in pancreatic islets isolated from pups of diabetic mice [44]. In addition, murine diabetes influenced placental expression of Igf2 [45]. Murine diabetes is induced by intraperitoneal injection of streptozotocin and is characterized by poor maternal nutritional condition and low pup weight. The birth weight is usually higher in GDM than control as demonstrated in the current investigation. The differences in maternal disorder (GDM versus streptozotocin-induced diabetes), maternal nutrition condition (good versus poor), species (human versus murine) and birth weight are the possible factors responsible for the different methylation in IGF2 MDR observed in humans and mice.

\section{Conclusion}

In summary, we reported that GDM induced significantly increased methylation levels at fetal GNAS DMR compared with control, suggesting that hypermethylation at GNAS DMR may be among the mechanisms linking maternal GDM with high risk for chronic diseases in later life of offspring. Further investigation is needed to clarify the exact role of GNAS in the development of obesity and hypertension and to identify possible target point for the reduction of the risk for metabolic diseases in later life of GDM fetuses.

\section{Abbreviations \\ IGF2: Insulin-like growth factor-2; GNAS: Guanine nucleotide binding protein, alpha stimulating; DMR: Differentially methylated region; DNA: Deoxyribonucleicacid; EDTA: Ethylene Diamine Tetraacetic Acid; SGA: Small for gestational age; AGA: Appropriate for gestational age; IADPSG: International Association of Diabetes and Pregnancy Study Groups; PCR: Poly-chain reaction.}

\section{Competing interests}

The authors declare that they have no competing interests.

\section{Authors' contributions}

DC participated in experiment design, data analysis and draft of the manuscript. AZ participated the experiment, data analysis and drafted and revised the manuscript. MF participated in obtain, analysis and interpretation of data. RF participated in obtain, analysis and interpretation of data. JM 
participated in obtain, analysis and interpretation of data. YJ participated in obtain, analysis and interpretation of data. $\mathrm{HZ}$ carried out quantitative assay of DNA methylation and data anlysis. CH participated sample collection, experiment and data analysis. XY participated sample collection, experiment and data analysis. $\mathrm{HH}$ conceived the study, participated its design and criticized the manuscript. YL conceived the study and design, and drafted and revised the manuscript. MD conceived the study and design, coordinated the whole procedures and drafted and revised manuscript. All authors read and approved the final manuscript.

\section{Acknowledgements}

This work was supported by National Basic Research Program of China (2012CB944903) and Natural Scientific Foundation of China (81170587 and 81170572)

\begin{abstract}
Author details
'Women's Hospital, School of Medicine, Zhejiang University, 1 Xueshi Road, Hangzhou 310006, Zhejiang Province, China. ${ }^{2}$ Bio-X Institutes, Key Laboratory for the Genetics of Developmental and Neuropsychiatric Disorders, Ministry of Education, Shanghai Jiao Tong University, Shanghai, China. ${ }^{3}$ Shaoxing Women and Children's Hospital, Shaoxing, China. ${ }^{4}$ Huzhou Maternity and Child Care Hospital, Huzhou, China. ${ }^{5}$ Jiaxing Maternity and Child Care Hospital, Jiaxing, China. ${ }^{6}$ Ningbo Women and Children's Hospital, Ningbo, China. 'Institutes of Biomedical Sciences, Fudan University, Shanghai, China. ${ }^{8}$ Department of Biochemistry and Molecular Biology, Key Laboratory of Molecular Medicine, The Ministry of Education, Fudan University Shanghai Medical College, 303 Mingdao Building, 138 Yixueyuan Road, Shanghai 200032, PR China. ${ }^{9}$ Key Laboratory of Reproductive Genetics, Ministry of Education, Zhejiang University, Hangzhou, China. ${ }^{10}$ Key Laboratory of Women's Reproductive Health of Zhejiang Province, Hangzhou, China.
\end{abstract}

Received: 26 June 2014 Accepted: 24 September 2014

Published online: 01 October 2014

\section{References}

1. Schneider S, Bock C, Wetzel M, Maul H, Loerbroks A: The prevalence of gestational diabetes in advanced economies. J Perinat Med 2012, 40(5):511-520

2. Ben-Haroush A, Yogev Y, Hod M: Epidemiology of gestational diabetes mellitus and its association with Type 2 diabetes. Diabet Med 2004, 21(2):103-113.

3. Crowther CA, Hiller JE, Moss JR, McPhee AJ, Jeffries WS, Robinson JS: Effect of treatment of gestational diabetes mellitus on pregnancy outcomes. N Engl J Med 2005, 352(24):2477-2486.

4. Wendland EM, Torloni MR, Falavigna M, Trujillo J, Dode MA, Campos MA, Duncan BB, Schmidt Ml: Gestational diabetes and pregnancy outcomes-a systematic review of the World Health Organization (WHO) and the International Association of Diabetes in Pregnancy Study Groups (IADPSG) diagnostic criteria. BMC Pregnancy Childbirth 2012, 12:23.

5. Gillman MW, Rifas-Shiman S, Berkey CS, Field AE, Colditz GA: Maternal gestational diabetes, birth weight, and adolescent obesity. Pediatrics 2003, 111(3):e221-e226.

6. Lawlor DA, Fraser A, Lindsay RS, Ness A, Dabelea D, Catalano P, Davey Smith G, Sattar N, Nelson SM: Association of existing diabetes, gestational diabetes and glycosuria in pregnancy with macrosomia and offspring body mass index, waist and fat mass in later childhood: findings from a prospective pregnancy cohort. Diabetologia 2010, 53(1):89-97.

7. Catalano PM, Farrell K, Thomas A, Huston-Presley L, Mencin P, de Mouzon SH, Amini SB: Perinatal risk factors for childhood obesity and metabolic dysregulation. Am J Clin Nutr 2009, 90(5):1303-1313.

8. Malcolm J: Through the looking glass: gestational diabetes as a predictor of maternal and offspring long-term health. Diabetes Metab Res Rev 2012, 28(4):307-311.

9. Dabelea D, Hanson RL, Lindsay RS, Pettitt DJ, Imperatore G, Gabir MM, Roumain J, Bennett PH, Knowler WC: Intrauterine exposure to diabetes conveys risks for type 2 diabetes and obesity: a study of discordant sibships. Diabetes 2000, 49(12):2208-2211.

10. Clausen TD, Mathiesen ER, Hansen T, Pedersen $O$, Jensen DM, Lauenborg J, Schmidt L, Damm P: Overweight and the metabolic syndrome in adult offspring of women with diet-treated gestational diabetes mellitus or type 1 diabetes. J Clin Endocrinol Metab 2009, 94(7):2464-2470.
11. Silverman $\mathrm{BL}$, Metzger $\mathrm{BE}$, Cho NH, Loeb CA: Impaired glucose tolerance in adolescent offspring of diabetic mothers. relationship to fetal hyperinsulinism. Diabetes Care 1995, 18(5):611-617

12. Vaarasmaki M, Pouta A, Elliot $P$, Tapanainen $P$, Sovio U, Ruokonen A, Hartikainen AL, McCarthy M, Jarvelin MR: Adolescent manifestations of metabolic syndrome among children born to women with gestational diabetes in a general-population birth cohort. Am J Epidemiol 2009, 169(10):1209-1215

13. Aerts $L$, Van Assche FA: Animal evidence for the transgenerational development of diabetes mellitus. Int J Biochem Cell Biol 2006, 38(5-6):894-903.

14. Vrachnis N, Antonakopoulos N, lliodromiti Z, Dafopoulos K, Siristatidis C, Pappa Kl, Deligeoroglou E, Vitoratos N: Impact of maternal diabetes on epigenetic modifications leading to diseases in the offspring. Exp Diabetes Res 2012, 2012:538474.

15. Waterland RA, Jirtle RL: Early nutrition, epigenetic changes at transposons and imprinted genes, and enhanced susceptibility to adult chronic diseases. Nutrition 2004, 20(1):63-68.

16. Ruchat SM, Houde AA, Voisin G, St-Pierre J, Perron P, Baillargeon JP, Gaudet D, Hivert MF, Brisson D, Bouchard L: Gestational diabetes mellitus epigenetically affects genes predominantly involved in metabolic diseases. Epigenetics 2013, 8(9):935-943.

17. El Hajj N, Pliushch G, Schneider E, Dittrich M, Muller T, Korenkov M, Aretz M, Zechner $U$, Lehnen $\mathrm{H}$, Haaf T: Metabolic programming of MEST DNA methylation by intrauterine exposure to gestational diabetes mellitus. Diabetes 2013, 62(4):1320-1328.

18. Houde AA, Guay SP, Desgagne V, Hivert MF, Baillargeon JP, St-Pierre J, Perron P, Gaudet D, Brisson D, Bouchard L: Adaptations of placental and cord blood ABCA1 DNA methylation profile to maternal metabolic status. Epigenetics 2013, 8(12):1289-1302.

19. Cui H, Cruz-Correa M, Giardiello FM, Hutcheon DF, Kafonek DR, Brandenburg S, Wu Y, He X, Powe NR, Feinberg AP: Loss of IGF2 imprinting: a potential marker of colorectal cancer risk. Science 2003, 299(5613):1753-1755.

20. Murrell A, Ito Y, Verde G, Huddleston J, Woodfine K, Silengo MC, Spreafico F, Perotti D, De Crescenzo A, Sparago A, Cerrato F, Riccio A: Distinct methylation changes at the IGF2-H19 locus in congenital growth disorders and cancer. PLoS One 2008, 3(3):e1849.

21. Cooley SM, Donnelly JC, Geary MP, Rodeck CH, Hindmarsh PC: Maternal insulin-like growth factors 1 and 2 (IGF-1, IGF-2) and IGF BP-3 and the hypertensive disorders of pregnancy. J Matern Fetal Neonatal Med 2010, 23(7):658-661.

22. Tobi EW, Heijmans BT, Kremer D, Putter H, de Waal HA D-v, Finken MJ, Wit JM, Slagboom PE: DNA methylation of IGF2, GNASAS, INSIGF and LEP and being born small for gestational age. Epigenetics 2011, 6(2):171-176.

23. Williamson CM, Ball ST, Nottingham WT, Skinner JA, Plagge A, Turner MD, Powles N, Hough T, Papworth D, Fraser WD, Maconochie M, Peters J: A cis-acting control region is required exclusively for the tissue-specific imprinting of Gnas. Nat Genet 2004, 36(8):894-899.

24. Heijmans BT, Tobi EW, Stein AD, Putter H, Blauw GJ, Susser ES, Slagboom PE, Lumey LH: Persistent epigenetic differences associated with prenatal exposure to famine in humans. Proc Natl Acad Sci U S A 2008, 105(44):17046-17049.

25. Tobi EW, Lumey LH, Talens RP, Kremer D, Putter H, Stein AD, Slagboom PE, Heijmans BT: DNA methylation differences after exposure to prenatal famine are common and timing- and sex-specific. Hum Mol Genet 2009, 18(21):4046-4053.

26. Lillycrop KA, Phillips ES, Torrens C, Hanson MA, Jackson AA, Burdge GC: Feeding pregnant rats a protein-restricted diet persistently alters the methylation of specific cytosines in the hepatic PPAR alpha promoter of the offspring. Br J Nutr 2008, 100(2):278-282.

27. Sinclair KD, Allegrucci C, Singh R, Gardner DS, Sebastian S, Bispham J, Thurston A, Huntley JF, Rees WD, Maloney CA, Lea RG, Craigon J, McEvoy TG, Young LE: DNA methylation, insulin resistance, and blood pressure in offspring determined by maternal periconceptional B vitamin and methionine status. Proc Natl Acad Sci U S A 2007, 104(49):19351-19356.

28. He J, Zhang A, Fang M, Fang $R$, Ge J, Jiang $Y$, Zhang H, Han C, Ye X, Yu D, Huang H, Liu Y, Dong M: Methylation levels at IGF2 and GNAS DMRs in infants born to preeclamptic pregnancies. BMC Genomics 2013, 14:472.

29. Weinstein LS, Xie T, Qasem A, Wang J, Chen M: The role of GNAS and other imprinted genes in the development of obesity. Int J Obes (Lond) 2010, 34(1):6-17.

30. Weinstein LS, Chen M, Xie T, Liu J: Genetic diseases associated with heterotrimeric G proteins. Trends Pharmacol Sci 2006, 27(5):260-266. 
31. Turner ST, Boerwinkle E, O'Connell JR, Bailey KR, Gong Y, Chapman AB, McDonough CW, Beitelshees AL, Schwartz GL, Gums JG, Padmanabhan S, Hiltunen TP, Citterio L, Donner KM, Hedner T, Lanzani C, Melander O, Saarela J, Ripatti S, Wahlstrand B, Manunta P, Kontula K, Dominiczak AF, Cooper-Dehoff RM, Johnson JA: Genomic association analysis of common variants influencing antihypertensive response to hydrochlorothiazide. Hypertension 2013, 62(2):391-397.

32. Jia H, Hingorani AD, Sharma P, Hopper R, Dickerson C, Trutwein D, Lloyd $D D$, Brown MJ: Association of the G(s)alpha gene with essential hypertension and response to beta-blockade. Hypertension 1999, 34(1):8-14.

33. Ehret GB, Munroe PB, Rice KM, Bochud M, Johnson AD, Chasman DI, Smith $A V$, Tobin MD, Verwoert GC, Hwang SJ, Nilsson P, Smith GD, Wong A, Narisu N, Stancakova A, Raffel L, Yao J, Kathiresan S, O'Donnell CJ, Schwartz SM, Ikram MA, Longstreth WT Jr, Mosley TH, Seshadri S, Shrine NR, Wain LV, Morken MA, Swift AJ, Laitinen J, Prokopenko I, et al: Genetic variants in novel pathways influence blood pressure and cardiovascular disease risk. Nature 2011, 478(7367):103-109.

34. Faienza MF, Santoro N, Lauciello R, Calabro R, Giordani L, Di Salvo G, Ventura A, Delvecchio M, Perrone L, Del Giudice EM, Cavallo L: IGF2 gene variants and risk of hypertension in obese children and adolescents. Pediatr Res 2010, 67(4):340-344.

35. Metzger BE, Gabbe SG, Persson B, Buchanan TA, Catalano PA, Damm P, Dyer AR, Leiva A, Hod M, Kitzmiler JL, Lowe LP, McIntyre HD, Oats JJ, Omori Y, Schmidt MI: International association of diabetes and pregnancy study groups recommendations on the diagnosis and classification of hyperglycemia in pregnancy. Diabetes Care 2010, 33(3):676-682.

36. Germain-Lee EL, Ding CL, Deng Z, Crane JL, Saji M, Ringel MD, Levine MA: Paternal imprinting of Galpha(s) in the human thyroid as the basis of TSH resistance in pseudohypoparathyroidism type 1a. Biochem Biophys Res Commun 2002, 296(1):67-72.

37. Weinstein $L S, Y u S$, Warner DR, Liu J: Endocrine manifestations of stimulatory $\mathrm{G}$ protein alpha-subunit mutations and the role of genomic imprinting. Endocr Rev 2001, 22(5):675-705.

38. Yu S, Gavrilova O, Chen H, Lee R, Liu J, Pacak K, Parlow AF, Quon M, Reitman ML, Weinstein LS: Paternal versus maternal transmission of a stimulatory G-protein alpha subunit knockout produces opposite effects on energy metabolism. J Clin Invest 2000, 105(5):615-623.

39. Perera F, Herbstman J: Prenatal environmental exposures, epigenetics, and disease. Reprod Toxicol 2011, 31(3):363-373.

40. St-Pierre J, Hivert MF, Perron P, Poirier P, Guay SP, Brisson D, Bouchard L: IGF2 DNA methylation is a modulator of newborn's fetal growth and development. Epigenetics 2012, 7(10):1125-1132.

41. Hoyo C, Fortner K, Murtha AP, Schildkraut JM, Soubry A, Demark-Wahnefried W, Jirtle RL, Kurtzberg J, Forman MR, Overcash F, Huang Z, Murphy SK: Association of cord blood methylation fractions at imprinted insulin-like growth factor 2 (IGF2), plasma IGF2, and birth weight. Cancer Causes Control 2012, 23(4):635-645.

42. Steegers-Theunissen RP, Obermann-Borst SA, Kremer D, Lindemans J, Siebel C, Steegers EA, Slagboom PE, Heijmans BT: Periconceptional maternal folic acid use of 400 microg per day is related to increased methylation of the IGF2 gene in the very young child. PLoS One 2009, 4(11):e7845

43. Shao WJ, Tao LY, Gao C, Xie JY, Zhao RQ: Alterations in methylation and expression levels of imprinted genes $\mathrm{H} 19$ and Igf2 in the fetuses of diabetic mice. Comp Med 2008, 58(4):341-346.

44. Ding GL, Wang FF, Shu J, Tian S, Jiang Y, Zhang D, Wang N, Luo Q, Zhang $Y$, Jin F, Leung PC, Sheng JZ, Huang HF: Transgenerational glucose intolerance with $\operatorname{lgf} 2 / \mathrm{H} 19$ epigenetic alterations in mouse islet induced by intrauterine hyperglycemia. Diabetes 2012, 61(5):1133-1142.

45. Yu Y, Singh U, Shi W, Konno T, Soares MJ, Geyer R, Fundele R: Influence of murine maternal diabetes on placental morphology, gene expression, and function. Arch Physiol Biochem 2008, 114(2):99-110.

doi:10.1186/s12881-014-0108-3

Cite this article as: Chen et al:: Increased methylation at differentially methylated region of GNAS in infants born to gestational diabetes. BMC Medical Genetics 2014 15:108.

\section{Submit your next manuscript to BioMed Central and take full advantage of:}

- Convenient online submission

- Thorough peer review

- No space constraints or color figure charges

- Immediate publication on acceptance

- Inclusion in PubMed, CAS, Scopus and Google Scholar

- Research which is freely available for redistribution

Submit your manuscript at www.biomedcentral.com/submit
C Biomed Central 